\title{
Un bon signe de reperfusion
}

\section{A good sign of reperfusion}

\section{P. Taboulet}

Reçu le 28 janvier 2011 ; accepté le 11 février 2011

(C) SFMU et Springer-Verlag France 2011

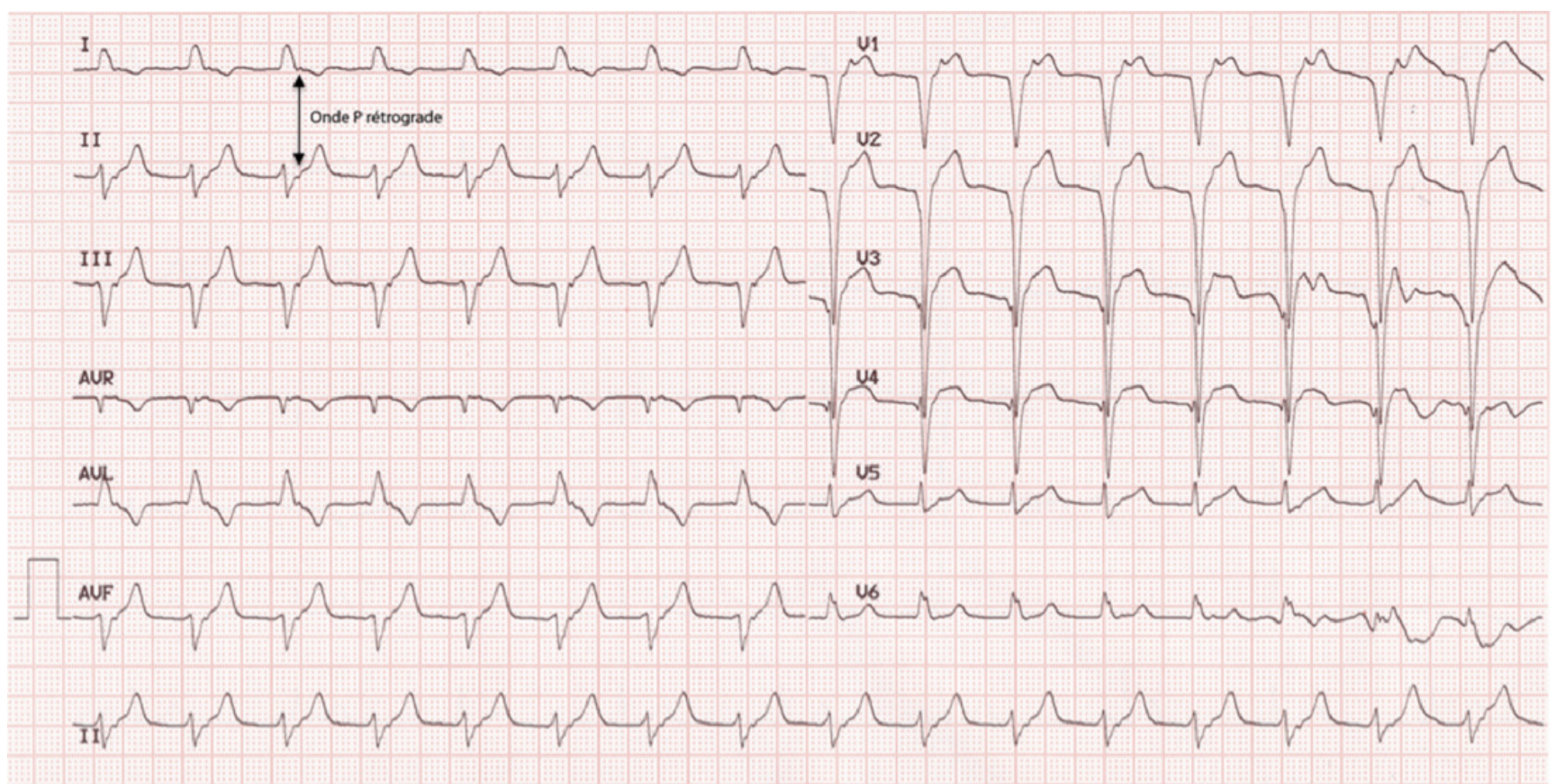

Légende : Un patient de 51 ans consulte aux urgences pour des brûlures épigastriques matinales. L'examen clinique est sans particularité, la douleur s'est atténuée. Les ECG inscrivent, pendant 45 minutes consécutives, un rythme idioventriculaire accéléré (Riva) à 96/min : il n'y a pas d'onde $\mathrm{P}$ antérograde, la durée des QRS est de $140 \mathrm{~ms}$ avec retard gauche différent d'un bloc de branche gauche (car la pente descendante de $\mathrm{S}$ en V1 est plus rapide que la pente ascendante, ce qui signe son origine ventriculaire). Une onde $\mathrm{P}$ rétrograde est probable derrière chaque $\mathrm{QRS}$. Une ischémie myocardique peut être évoquée devant des ondes $\mathrm{T}$ plus amples que les deux tiers de l'amplitude des QRS en

\section{P. Taboulet $(\bowtie)$}

Urgences, hôpital Saint-Louis,

1 , avenue Claude-Vellefaux,

F-75010 Paris, France

e-mail : pierre.taboulet@sls.aphp.fr territoire inférieur. Les Riva sont des rythmes accélérés qui naissent par hyperautomatisme ectopique. Ils apparaissent habituellement à la phase de reperfusion d'un infarctus du myocarde ou au décours d'un arrêt cardiaque, plus rarement au cours d'une cardiomyopathie ou une intoxication digitalique. Ils peuvent masquer - mais pas totalement — les signes ECG de souffrance ischémique du myocarde. Bien tolérés, ils cèdent de façon spontanée et ne nécessitent en général aucun traitement [1]. La coronarographie a confirmé l'occlusion incomplète de l'interventriculaire antérieure.

\section{Référence}

1. Riera AR, Barros RB, de Sousa FD, et al (2010) Accelerated idioventricular rhythm: history and chronology of the main discoveries. Indian Pacing Electrophysiol J 10:40-8 